\title{
Experimental Studies on the Influence of Electrochemical Dimensional Processing on the Surface Fatigue of Rolls in Rolling Machines
}

\author{
Alexander A. Boldyrev ${ }^{1, *}$, Alexander I. Boldyrev ${ }^{1}$, Alla V. Perova ${ }^{1}$, and Anna A. Padurets ${ }^{1}$ \\ ${ }^{1}$ Voronezh State Technical University, 14, Moscow Avenue, 394026, Voronezh, Russia
}

\begin{abstract}
The state of surface layer in large part determines the performance characteristics of products, especially those operating at high contact loads, and in particular of rolls in rolling machines. As a rule, grinding is the final processing of rolls, but high specific work and high local heating in the cutting area lead to the appearance of a large variety of defects in the surface layer of the machined part. Subsequent electrochemical dimensional processing can significantly reduce their number.

This article presents the results of comparative tests for surface fatigue of samples made of alloy steel $9 \mathrm{Cr} 2 \mathrm{MoV}$. The sequence of samples preparation for experimental studies is considered, they underwent a cycle of heat treatment according to a single standard mode, which made it possible to obtain a martensitic structure in the presence of inclusions of small carbides. Then the samples were ground to the height of irregularities $\mathrm{Ra} \quad=\quad 0.3-0.2$ microns. Some of the ground samples were subjected to electrochemical dimensional processing at rational modes, when $0.2 \mathrm{~mm}$ thick metal layer was removed per side in the time equal to $0.5 \mathrm{~min}$. The result was practically flaw-free surface with the microroughness height $\mathrm{Ra}=0.25$ 0.18

microns.

The sample tests for surface fatigue were carried out on a two-contact roller machine under rolling conditions with relative slip between the sample surface and pressure rollers at the peripheral speed of sample rotation 1.3 times lower than the circumferential speed of pressure roller rotation. The analysis on the contact stress diagram of the samples showed that higher resistance to fatigue fractures is observed in the samples after electrochemical dimensional processing. The number of cycles at which the limit of material contact endurance occurs for these samples is almost twice as large as for the samples after grinding.
\end{abstract}

\section{Introduction}

It is known [1-3], that operational properties of the working surfaces in highly loaded machine parts largely depend on the way they are processed, especially in finishing

\footnotetext{
*Corresponding author: alexboldyrev@yandex.ru
} 
operations. Grinding is the most common finish for mill rolls. The characteristic features of grinding cutting process are extensive specific work and high local heating in the cutting area, leading to the appearance of scratches, tears, residual stresses, work hardening, structural changes in the metal in the surface layer of the processed surface $[4,5]$. All these defects lead to a decrease in the contact fatigue of rolls. They can be eliminated by electrochemical dimensional treatment during anodic dissolution to the depth exceeding the thickness of defective surface layer [6-8].

In this work, the authors try to evaluate the results of comparative tests for contact fatigue of samples, the working surface of which was obtained by grinding with subsequent electrochemical dimensional processing.

\section{Preparing Samples for Test}

The samples, geometric parameters of which are shown in Fig. 1, were made of alloy steel $9 \mathrm{Cr} 2 \mathrm{MoV}$, which is used for work rolls of cold rolling metal machines under especially severe operating conditions. The chemical composition of the steel corresponded to the national standard GOST $3541-57(0.9 \% \mathrm{C}, 1.9 \% \mathrm{Cr}, 0.4 \% \mathrm{Si}, 0.5 \% \mathrm{Mn}, 0.2 \% \mathrm{~V}, 0.3 \%$ Mo). All samples were made from billets of the same melt and underwent the heat treatment cycle according to the single standard mode: quenching (heating to $800{ }^{\circ} \mathrm{C}$, holding for 1.5 hours, cooling in oil); tempering (heating up to $180^{\circ} \mathrm{C}$, holding for 3 hours, cooling in air). As a result of such heat treatment, the samples had martensitic structure with the presence of small carbides inclusions, hardness 61-62 HRC.
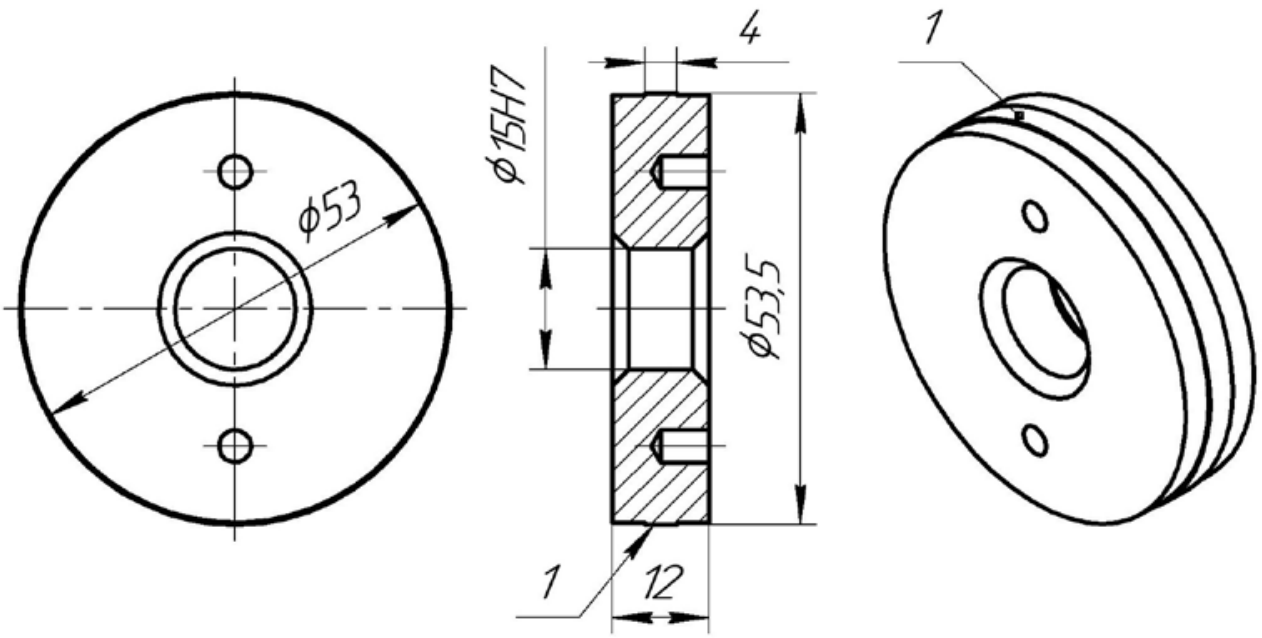

Fig. 1. Sample for testing for contact fatigue: 1 - working surface

The samples were ground on cylindrical grinding machine model 3A164 with $25 \mathrm{aF} 46 \mathrm{~K} 6 \mathrm{~V}$ wheels according to the standard technology of processing rolls made of this steel. The processing was carried out under the following conditions and modes of grinding: peripheral speed of the wheel $-32 \mathrm{~m} / \mathrm{s}$; sample circumferential speed $-20.7 \mathrm{~m} / \mathrm{s}$; longitudinal feed $-1.4 \mathrm{~m} / \mathrm{min}$; grinding depth $-0.015 \mathrm{~mm} / \mathrm{stroke}$. The final processing of the samples working surfaces was carried out when removing the $0.15 \mathrm{~mm}$ allowance with the minimum transverse feed of $0.005 \mathrm{~mm} /$ stroke. The grinding of samples was completed after the termination of sparking in processing area. The height of irregularities after grinding was in the range of $\mathrm{Ra}=0.3-0.2$ microns, which corresponded to the 9th roughness grade. 


\section{Electrochemical Dimensional Processing of Samples}

Electrochemical dimensional processing of samples was carried out on the electrochemical processing machine of 901 model in a special chamber. The sample was mounted on the current-conducting shaft of the chamber in such a way that the electrolyte flow passed only through the interelectrode gap on both its sides. The following conditions and modes of electrochemical dimensional processing of the preliminary polished surface of the samples were created [9]: current density - $40 \mathrm{~A} / \mathrm{cm} 2$; voltage at the electrodes - $22 \mathrm{~V}$; average interelectrode gap - $0.2 \mathrm{~mm}$; rotation frequency of samples - $200 \mathrm{rpm}$; electrolyte $-15 \%$ sodium chloride solution; electrolyte temperature - $20-25{ }^{\circ} \mathrm{C}$; the electrolyte supply pressure to the working chamber - 0.40-4.5 MPa. The welding transformer of the $300 \mathrm{M}$ type was used as direct current source. In the process of electrochemical dimensional processing, the metal layer $0.2 \mathrm{~mm}$ thick was removed per side in the time of $0.5 \mathrm{~min}$. The roughness of the treated surface also corresponded to the 9th roughness grade with the height of microroughness $\mathrm{Ra}=0.25-0.18$ microns [9].

\section{Contact Fatigue Tests}

Tests of specimens for contact fatigue were carried out on a two-contact roller machine with a power of $8 \mathrm{~kW}$, with pressure rollers (upper and lower) made of high-speed heattreated steel HS18-0-1 (1.3355), according to the scheme shown in Fig. 2. Load P, acting on the upper pressure roller with radius R1, was transferred to the sample with radius R2 and then to the lower roller. Thus, in one revolution, each point of the sample surface was subjected to two loads. The tests were carried out in rolling conditions with relative sliding between the sample surface and the pressure rollers at peripheral speed of sample rotation 1.3 times lower than the circumferential speed of rotation of the pressure roller, the rotation speed of which was $1000 \mathrm{rpm}$. The criterion for tests end was the beginning of progressive spalling of the investigated sample surface. The tests were carried out on 106 cycles basis.

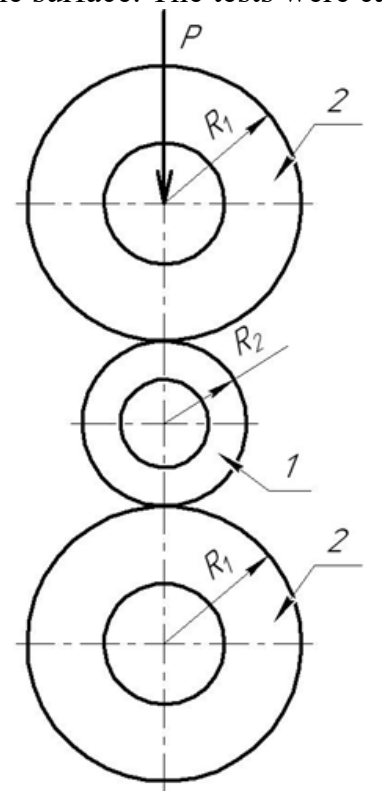

Fig. 2. Scheme of testing samples for contact fatigue: 1 - sample; 2 - pressure rollers 
Contact stresses were determined depending on the value of the load acting on the pressure roller, according to the Hertz-Belyaev formula [10].

The test results are shown in Fig. 3. Analysis of the contact stress diagram of the samples showed that higher resistance to fatigue fractures is observed in samples after electrochemical dimensional processing. The number of cycles, at which the limit of contact fatigue of the material occurs for such samples, is almost twice as large as for samples after grinding.

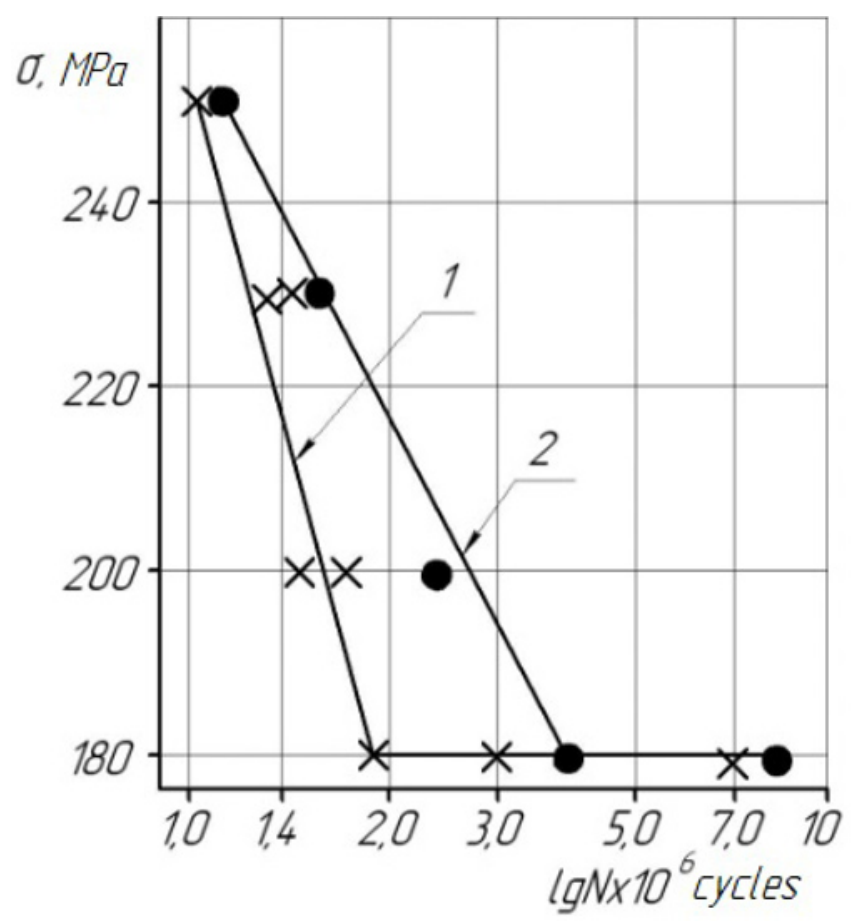

Fig. 3. Sample contact stress diagram: 1 - after grinding; 2 - after electrochemical sizing

When comparing profilograms taken from the surface of the samples before and after testing at different contact stresses, more significant changes in the microgeometry of the ground surface are found. For example, if in polished samples after testing at contact stresses equal to $180 \mathrm{MPa}$, the surface roughness deteriorated in comparison with the initial one by 2 times, then in the samples processed by the electrochemical method no more than 1.5 times, despite the twice as many loading cycles.

\section{Results and Conclusions}

The increase in surface contact fatigue after electrochemical dimensional processing can be explained by the superior structure of its surface layer due to the removal of defects formed during grinding.

Evaluation of the achieved results of comparative tests for contact fatigue of samples showed high agreement with the results of similar studies for other highly loaded products [11-12].

The obtained research results reveal the possibility of a significant increase in the operational characteristics of rolls and other parts operating with contact loads during rolling with slip. 


\section{References}

1. V.A. Lebedev, A.V. Kirichek, L.V. Chunakhova, Effectiveness of Application of Additional Strengthening Processing of Surface Plastic Deformation on Increase in Fatigue Life of Parts, Lecture Notes in Mechanical Engineering (2020)

2. A.I. Boldyrev, A.A. Boldyrev, O.N. Fedonin, Strengthening of materials by vibroimpact and combined methods with previous electrochemical processing, MATEC Web of Conferences, 224, 01097 (2018)

3. A.I. Boldyrev, A.V. Kuzovkin, A.A. Boldyrev, A.A. Padurets, Surface layer formation at dynamic combined exposure by two-component electrode, IOP Conference Series: Materials Science and Engineering, 1029(1), 012007 (2021)

4. M. Tamarkin, E. Tishchenko, A. Azarova, V. Butenko, Surface quality formation at polymer composite details' abrasive processing, IOP Conference Series: Materials Science and Engineering, 918(1), 012114 (2020)

5. A.V. Kirichek, S.V. Barinov, A.V. Yashin, Improving the mechanical and operational characteristics of aluminum alloys by multi-contact deformation treatment, IOP Conference Series: Materials Science and Engineering, 971(4), 042053 (2020)

6. V.P. Smolentsev, Technology for electrochemical treatment of internal surfaces, Moscow, Mechanical Engineering (1976)

7. O.V. Skrygin, V.P. Smolentsev, E.A. Saltanaeva, Preparing Automated of Software Complex for Technological Processes with Imposition of Electric Field, Lecture Notes in Mechanical Engineering (2020)

8. V.P. Smolentsev, V.V. Ivanov, E.V. Panichev, Technology of Combined ChemicalMechanical Processing, Lecture Notes in Mechanical Engineering (2020)

9. A.I. Boldyrev, Influence of operating parameters of the anodic dissolution process on ensuring the quality of electrochemical shaping, MATEC Web of Conferences, Part 13, 4 (2017)

10. A.S. Ivanov, We design mechanisms step by step, Part 1, Moscow, Publishing house of MSTU im. N.E. Bauman (2003)

11. A.G. Suslov, Yu.V. Gulyaev, A.M. Dalskiy, etc. The quality of the machines. Handbook, Part 2, Moscow, Mechanical Engineering (1995)

12. A.G. Suslov, V.F. Bezyazychniy, B.M. Bazrov, etc. Technologist's Handbook, Moscow, Innovative mechanical engineering (2019)

13. A.G. Suslov, V.P. Fedorov, O.A. Gorlenko, etc. Technological support and improvement of the operational properties of parts and their connections, Moscow, Mechanical Engineering (2008) 